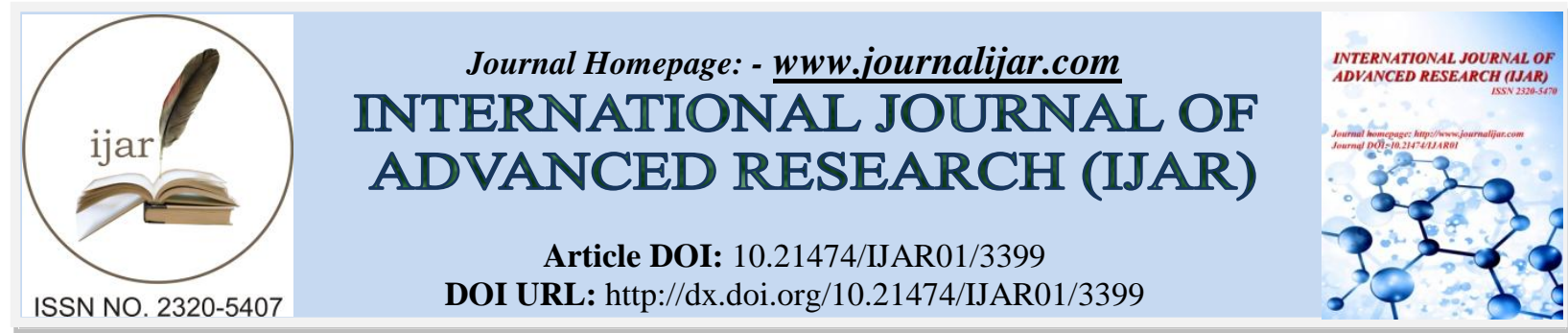

RESEARCH ARTICLE

\title{
CERVICAL CERCLAGE: SILK Vs NYLON SUTURE.
}

*Simmi Arora ${ }^{1}$ and TM Panchanadikar ${ }^{2}$.

1. Resident, Department of Obstetrics and Gynaecology, Bharati Vidyapeeth Deemed University Medical College, Pune, Maharashtra, India.

2. Professor, Department of Obstetrics and Gynaecology, Bharati Vidyapeeth Deemed University Medical College, Pune, Maharashtra, India.

\section{Manuscript Info}

\section{Manuscript History}

Received: 17 December 2016

Final Accepted: 20 January 2017

Published: February 2017

Key words:-

Cervical Cerclage, Fibrosis, Nylon

Sutures, Pre-term delivery, Silk Sutures

\section{Abstract}

Introduction:The term 'cervical incompetence' is used to describe a disorder in which painless cervical dilatation led to recurrent second trimester pregnancy losses.Structural weakness of cervical tissue was thought to cause or contribute to these adverse outcomes.Cervical cerclageis used for the treatment of cervical incompetence. The relatively muscular and elastic internal Os is responsible for retaining the pregnancy in utero and a cerclage represents an attempt to physically support a weakened cervix. Though various studies have proven the efficacy of cerclage procedure, a number of questions still exist. What is the effect of the type of suture on the cervix? Is there any difference in the outcome following cervical cerclage with a multifilament suture, compared to a monofilament suture? The present study was thus conducted with the objective of comparing difference in cervical cerclage by silk and nylon as a suture material in terms of operability and outcome. The intention is to know the difference between monofilament and multifilament suture.

Materials \& Methods: A Randomized control study was conducted in the Department of Obstetrics and Gynecology of a Tertiary Care Hospital and Medical college. After fulfilling the inclusion and exclusion criteria, total 50 cases of cervical length less than $3 \mathrm{cms}$ were selected and divided into two groups randomly using table of random numbers: Nylon Group: McDonald cerclage procedure using nylon sutures (25 patients) and; Silk group:McDonald cerclage procedure using silk sutures (25 patients). The patients were compared with respect to time taken for procedure, intra-op complications, ease of operability and ease of stitch removal. All the patients were followed up till delivery as per routine ANC schedule and development of fibrosis and outcome were compared. Data was analyzed using SPSS software ver. 21.

Results: The mean age and weeks of gestation in nylon group was $23.80 \pm 2.71$ years and 20.66 weeks whereas in the silk group was $23.24 \pm 3.19$ years and 21.41 weeks $(\mathrm{p}-0.507,0.051)$. The mean time taken for the procedure in nylon group was $21.20 \pm 5.26 \mathrm{~min}$ whereas the mean time taken in silk group was $17.20 \pm 4.35 \mathrm{~min}(\mathrm{p}<0.01)$. No difference was observed between the study groups with respect to 
difficulty in operability and ease of suture removal $(p>0.05)$. Intra operative bleeding was significant in $24 \%$ women from nylon group and in $12 \%$ women in silk group (p-0.46) while Discharge and leakage was reported by $20 \%$ of cases each in nylon group and $12 \%$ and $20 \%$ cases in silk group (p-0.78). No difference was observed between the study groups with respect to development of fibrosis and outcome i.e. type of delivery ( $\mathrm{p}>0.05)$.

Conclusion: The average time taken for the procedure was lesser with silk sutures while significant fibrosis was associated with nylon sutures. Both the suture materials were comparable in terms of operability, complication rate and ease of removal and outcome.

Copy Right, IJAR, 2017,. All rights reserved.

\section{Introduction:-}

Cervical incompetence is defined as the weakness of the sphincter mechanism of the internal cervical os leading to painless effacement and dilatation of the cervix. This results in either mid-trimester pregnancy loss or pre term rupture of membranes or preterm labor and pregnancy failure. ${ }^{1}$

Despite major research efforts, more than 10 million births before 37 weeks of gestation occur annually worldwide, and more than 1 million infants die from this common complication of pregnancy (5-12\% incidence) ${ }^{2}$.

Cervical cerclage (tracheloplasty), also known as a cervical stitch, is used for the treatment of cervical incompetence (or insufficiency). The treatment consists of a strong suture being inserted into and around the cervix early in the pregnancy, usually between weeks 14 to 16, and then removed towards the end of the pregnancy when the greatest risk of miscarriage has passed.

Shirodkar introduced the application of transvaginal cervical cerclage as treatment of cervical incompetence in 1951. ${ }^{3}$ Initially, the operation was performed during pregnancy after the detection of a gradually yielding cervix seen in a woman who had entered seventh month of pregnancy. McDonald introduced his transvaginal cervical cerclage in $1957 .^{4}$ McDonald cervical cerclage was performed when dilatation of cervix and bulging fetal membranes were present during the second trimester of pregnancy.

Several observational studies into the efficacy of cervical cerclage have claimed high rate of successful pregnancy outcome in women with a poor obstetric history attributed to cervical incompetence. ${ }^{5,6}$ Cervical cerclage is probably effective in the prevention of mid-trimester miscarriage. Many case series quote a viable delivery rate of 70 to 90 percent after cerclage, compared with 10 to 30 percent prior to the procedure. ${ }^{7}$

The relatively muscular and elastic internal os is responsible for retaining the pregnancy in utero and a cerclage represents an attempt to physically support a weakened cervix. Though the intention is good in providing mechanical support to a weakened cervix, a number of questions still exist. What is the effect of the type of suture on the cervix? Is there any difference in the outcome following cervical cerclage with a multifilament suture, compared to a monofilament suture?

Different surgical suture materials used are: silk, nylon, polyester, polypropylene and polybutester. They are basically divided as monofilament and multifilament (braided/ unbraided). The Royal College Obstetricians and Gynaecologists in a most recent guideline in 2011 advised that the choice of suture material should be at the discretion of the surgeon. ${ }^{8}$

Silk suture is a multifilament, non-absorbable, sterile, surgical suture composed of an organic protein called fibroin. Its advantage is that it is best in handling and tying, however it has least tensile strength, high tissue reactivity, increases risk of infection due to high capillarity. ${ }^{9}$ Nylon sutures are synthetic non absorbable suture (monofilament). They have high tensile strength, minimal tissue reactivity and low cost. ${ }^{9}$ 
The present study was conducted with the objective of comparing difference in cervical cerclage by silk and nylon as a suture material in terms of operability and outcome. The intention is to know the difference between monofilament and multifilament suture.

\section{Material \& Methods:-}

A Randomized control study was conducted in the Department of Obstetrics and Gynecology of a Tertiary Care Hospital and Medical college. The study population included patients attending Antenatal clinic of the tertiary care Hospital with following inclusion and exclusion criteria:

\section{Inclusion Criteria:-}

After ruling out the contraindications of cervical cerclage, the pregnant patients attending antenatal clinic were selected with cervical length less than $3 \mathrm{cms}$ on ultrasound.

\section{Exclusion Criteria:-}

1. Emergency cervical cerclage

2. Patient with history of previous cervical cerclage

3. Any associated medical disorder of pregnancy

4. Active vaginal infection

\section{Sampling Technique:-}

After fulfilling the inclusion and exclusion criteria total 50 cases of cervical length less than $3 \mathrm{cms}$ were selected and divided into two groups randomly using table of random numbers.

- Nylon Group: McDonald cerclage procedure using nylon sutures (25 patients).

- Silk group: McDonald cerclage procedure using silk sutures (25 patients).

\section{Methodology:-}

Detail demographic history along with previous gynaecological and obstetrical history, physical examination and digital assessment of portiovaginalis of cervix was recorded on a pre-structured and pretested proforma. Base line investigations as for ANC were done mainly to rule out underlying medical disorders if detected. The McDonald cerclage procedure using nylon/ silk sutures was performed as per standard technique under general anaesthesia.

Patients were observed for 1 hour in the post-operative room. After shifting the patients to the ward, they were observed for FHS, Uterine contractions, voiding of urine/urinary retention and lower abdominal pain and leaking. Patients were advised bed rest with minimal mobilization i.e. allowed to be ambulated for their toileting and for meals. No tocolysis was given to any patients. Patients were advised to follow up after 8 days or to report immediately if any of the complaints like leaking, bleeding, contractions occur and were asked to follow up as per routine ANC schedule thereafter.

Primary outcome was the term delivery rate, preterm delivery rate before 37 weeks of gestation and percentage of cesarean section.

\section{Follow-up:-}

- Patients were followed up till delivery as per routine ANC schedule.

- Suture removal was done as follows:

$>$ At 37 completed weeks after confirmation of maturity.

$>$ If she has complains of leaking.

$>$ If she has gone into frank preterm labour.

- Associated complications, ease of removal of sutures and fibrosis at suture site if any was recorded. The amount of fibrosis was noted as follows:
$>$ Grade I - upto $25 \%$
$>$ Grade II - upto $50 \%$
$>$ Grade III - upto $75 \%$
$>$ Grade IV - whole cervical rim 


\section{Data Analysis:-}

Data was analyzed using SPSS 21.0 (SPSS Inc., Chicago, IL, USA) using appropriate statistical tests.

\section{Results:-}

The mean age and weeks of gestation in nylon group was $23.80 \pm 2.71$ years and 20.66 weeks whereas in the silk group was $23.24 \pm 3.19$ years and 21.41 weeks $(\mathrm{p}-0.507,0.051)$. It was observed that $68 \%$ women in nylon group were primi-gravida whereas $52 \%$ women in silk group were primi-gravida (p-0.387). The mean cervical length in nylon group was $2.15 \pm 0.42 \mathrm{~cm}$ and in silk group was $2.12 \pm 0.44 \mathrm{~cm}(\mathrm{p}-0.794)$ (Table 1$)$.

The mean time taken for the procedure in nylon group was $21.20 \pm 5.26$ min whereas the mean time taken in silk group was $17.20 \pm 4.35 \mathrm{~min}$ ( $\mathrm{p}<0.01$ ). Stitch was removed at $37.12 \pm 0.73$ weeks and $37.12 \pm 0.53$ weeks of gestation in nylon and silk group respectively (p-0.99) (Table 2).

No difference was observed between the study groups with respect to difficulty in operability and ease of suture removal ( $\mathrm{p}>0.05)$ (Table $3 \& 7)$.

Intra operative bleeding was significant in $24 \%$ women from nylon group and in $12 \%$ women in silk group (p-0.46) while Discharge and leakage was reported by $20 \%$ of cases each in nylon group and $12 \%$ and $20 \%$ cases in silk group (p-0.78) (Table $4 \& 5)$.

Significant fibrosis at the site of suture site was observed in $8 \%$ cases in nylon group whereas in $4 \%$ cases with fibrosis at the site of suture site were observed in silk group (Table 6).

Full term normal delivery occurred in $46 \%$ of nylon group and silk group each. LSCS was required in $24 \%$ of cases in nylon group and $20 \%$ of silk group (p-0.60) (Table 8).

Table 1:- Distribution of subjects based on baseline characteristics

\begin{tabular}{|c|c|c|c|c|}
\hline Variables & Group & Mean/ N & SD/ \% & p- value \\
\hline \multirow{2}{*}{ Age (yrs) } & Nylon & 23.80 & 2.71 & $\mathbf{0 . 5 0 7}$ \\
\cline { 2 - 4 } & Silk & 23.24 & 3.19 & \multirow{2}{*}{$\mathbf{0 . 0 5 1}$} \\
\hline \multirow{2}{*}{ Gestation Age (weeks) } & Nylon & 20.66 & 1.29 & \multirow{2}{*}{$\mathbf{0 . 3 8 7}$} \\
\cline { 2 - 4 } & Silk & 21.41 & $68 \%$ & $52 \%$ \\
\cline { 2 - 4 } Primi-gravida & Nylon & 17 & 0.42 & $\mathbf{0 . 7 9 4}$ \\
\cline { 2 - 4 } & Silk & 2.15 & 0.44 & \\
\hline
\end{tabular}

Table 2:- Distribution of subjects based on mean time for procedure and stitch removal

\begin{tabular}{|c|c|c|c|c|}
\hline Variables & Group & Mean & SD & p- value \\
\hline \multirow{2}{*}{$\begin{array}{c}\text { Time taken for } \\
\text { procedure }\end{array}$} & Nylon & 21.2 & 5.26 & $<0.01$ \\
\cline { 2 - 4 } $\begin{array}{c}\text { Week of Stitch } \\
\text { Removal }\end{array}$ & Silk & 17.2 & 4.35 & 0.73 \\
\cline { 2 - 4 } & Nylon & 37.12 & 0.53 & \multirow{2}{*}{} \\
\hline
\end{tabular}

Table 3:- Distribution of subjects based on Ease of operability.

\begin{tabular}{|l|c|c|c|c|}
\hline \multirow{2}{*}{ Operability } & Nylon & Group & \multirow{2}{*}{ Total } & p- value \\
\cline { 2 - 3 } & $19(76 \%)$ & $19(76 \%)$ & 38 & \multirow{2}{*}{$\mathbf{0 . 9 9}$} \\
\hline Easy & $4(16 \%)$ & $5(20 \%)$ & 9 & \\
\hline Moderate & $2(8 \%)$ & $1(4 \%)$ & 3 & \\
\hline Total & $25(100 \%)$ & $25(100 \%)$ & 50 & \\
\hline
\end{tabular}


Table 4:- Distribution of subjects based on Intra-op Bleeding.

\begin{tabular}{|l|c|c|c|c|}
\hline \multirow{2}{*}{$\begin{array}{l}\text { Intra-op } \\
\text { Bleeding }\end{array}$} & Nylon & \multirow{2}{*}{ Total } & \multirow{2}{*}{ p- value } \\
\cline { 2 - 4 } Significant & $6(24 \%)$ & $3(12 \%)$ & 9 & \multirow{2}{*}{$\mathbf{0 . 4 6 3}$} \\
\hline Minimal & $19(76 \%)$ & $22(88 \%)$ & 41 & \\
\hline Total & $25(100 \%)$ & $25(100 \%)$ & 50 & \\
\hline
\end{tabular}

Table 5:- Distribution of subjects based on post-op Complaints

\begin{tabular}{|l|c|c|c|c|}
\hline \multirow{2}{*}{ Complaints } & Nylon & Group & \multirow{2}{*}{ Total } & p-value \\
\cline { 2 - 4 } & $5(20 \%)$ & $3(12 \%)$ & 8 & \\
\hline Discharge & $5(20 \%)$ & $5(20 \%)$ & 0.78 \\
\\
\hline Neaking & $15(60 \%)$ & $17(68 \%)$ & 32 & \\
\hline Total & $25(100 \%)$ & $25(100 \%)$ & 50 & \\
\hline
\end{tabular}

Table 6:- Distribution of subjects based on Incidence of Fibrosis.

\begin{tabular}{|l|c|c|c|c|}
\hline \multirow{2}{*}{ Fibrosis at suture Site } & \multicolumn{2}{|c|}{ Group } & \multirow{2}{*}{ Total } & \multirow{2}{*}{ p- value } \\
\cline { 2 - 4 } & Nylon & Silk & & \\
\hline $\mathbf{7 5 - 1 0 0 \%}$ & $2(8 \%)$ & $1(4 \%)$ & $\mathbf{0 . 9 9}$ \\
\hline $\mathbf{5 0 \%}$ & $8(32 \%)$ & $10(40 \%)$ & 18 \\
\hline$<\mathbf{2 5 \%}$ & $15(60 \%)$ & $14(56 \%)$ & 29 \\
\hline Total & $25(100 \%)$ & $25(100 \%)$ & 50 & \\
\hline
\end{tabular}

Table 7:- Distribution of subjects based on Ease of stitch removal

\begin{tabular}{|l|c|c|c|c|}
\hline \multirow{2}{*}{$\begin{array}{l}\text { Ease of } \\
\text { Removal }\end{array}$} & Nylon & Silk & \multirow{2}{*}{ Total } & p- value \\
\cline { 2 - 4 } Easy & $21(84 \%)$ & $23(92 \%)$ & 44 & \multirow{2}{*}{$\mathbf{0 . 6 7}$} \\
\hline Difficult & $4(16 \%)$ & $2(8 \%)$ & 6 & \\
\hline Total & $25(100 \%)$ & $25(100 \%)$ & 50 & \\
\hline
\end{tabular}

Table 8:- Distribution of subjects based on Outcome.

\begin{tabular}{|l|c|c|c|c|}
\hline \multirow{2}{*}{ Outcome } & Nylon & Silk & \multirow{2}{*}{ Total } & p- value \\
\cline { 2 - 4 } & $15(60 \%)$ & $18(72 \%)$ & 33 & \multirow{2}{*}{ 0.606 } \\
\hline FTVD & $4(16 \%)$ & $2(8 \%)$ & 6 & \\
\hline LSCS & $6(24 \%)$ & $5(20 \%)$ & 50 & \\
\hline Total & $25(100 \%)$ & $25(100 \%)$ & & \\
\hline
\end{tabular}

\section{Discussion:-}

There are many surgeries that can be performed for cervical cerclage operation. The two main techniques of transvaginal cerclage are the McDonald method and the Shirodkar method. The McDonald's method is the most popular method in modern obstetrics. ${ }^{10}$ It is because of the ease with which it can be performed. In the present study, we performed all the cases by McDonald's method. Out of 50 cases, 25 surgeries were performed with silk and 25 with nylon.

In the study population, the mean age in nylon group was $23.80 \pm 2.71$ years whereas in the silk group was 23.24 \pm 3.19 years (p-0.507). Kaukab Naheed et al. ${ }^{11}$ studied the cases of cervical incompetence in their study and observed the mean age of presentation of 26years.

Out of all chosen patients, overall percentage of Primi-gravida patients was $60 \%$ and multigravida was $40 \%$. The lower percentage of multigravida can be attributed to the exclusion criteria i.e. patients with previous history of cervical cerclage. Also the other reason for more number of primi-gravida is incompetent os due to decrease muscular content (less than $10 \%) .{ }^{12}$ Less number of multigravida required encirclage because of the cervical changes related to age or previous injuries leading to fibrosis. ${ }^{13}$ 
The mean time taken for performing the procedure in nylon group was $21.20 \pm 5.26 \mathrm{~min}$. and the mean time taken in silk group was $17.20 \pm 4.35 \mathrm{~min}$. The average time was possible to calculate as a single surgeon has performed all the cases to remove operator bias. On an average, the time taken for performing the procedure in nylon group was 4 minutes more which was statistically significant. Therefore it can be concluded that the suturing time is less for silk easier knotting and gripping of the cervix with suture material.

The operability was easy in $76 \%$ cases in both nylon group and silk group. In $8 \%$ cases from nylon group and $4 \%$ cases in silk group the operability was reported to be difficult. However, the figures are insignificant as the difficult procedure was not because of the material used but because of the excessive shortening of cervix. Also, no significant intraoperative bleeding was seen in $82 \%$ of cases. We have considered bleeding to be significant when there was soaking of more than 2 swabs (4 layered). Patients in whom there was significant bleeding, 2/3rd cases were with nylon but it can be attributed to the trochar point needle which was used for nylon. Hence, it was not related to the suture material used per se. So, the difference was statistically insignificant.

The complications reported with cerclage include sepsis, premature rupture of membranes, premature labour, cervical dystocia, cervical laceration at delivery (11\% to $14 \%)$ and haemorrhage ${ }^{14-21}$. Discharge and leaking were the common complaints reported by patients in the present study. Discharge was reported by $20 \%$ of cases in nylon group and $12 \%$ cases in silk group. Discharge which was found in our case was not there with the infection because it was not foul smelling. There were limitations to our study that we could not send swab culture. The vaginal discharge which was present was because of diffuse tissue reaction of vaginal mucosa to suture material but the difference which was found in the present study is $20 \%$ with nylon and $12 \%$ in silk which was insignificant. Leaking was reported by $20 \%$ cases in both the groups showing that there is no difference.

Stitch removal was planned after confirming the maturity of the foetus. Average gestational age for stitch removal in both the groups was $37.12 \pm 0.73$ weeks (nylon) and $37.12 \pm 0.53$ weeks (silk) (p>0.05). Stitch removal in 6 patients who went in spontaneous preterm labour (PPROM) was not related with the amount of intraoperative bleeding or infection or type of suture material used. We removed the stitch in procedure room in all cases but in these 6 cases of leaking we removed suture in pre-labour room.

Significant fibrosis was present more in cases of nylon group (8\% vs 4\%), but with respect to overall fibrosis, it was not significant $(\mathrm{p}>0.05)$. According to some authors threaded silk in superficial and deep sutures has demonstrated some advantages over cotton suture. This is also a twisted multifilament suture, producing a less severe inflammatory reaction around the stitches, ${ }^{22-24}$ as compared with cotton. Among the synthetic suture materials, nylon undoubtedly produces the mildest tissue reaction. ${ }^{24,25}$ This is also a non-resorbable monofilament suture, and is widely used in sites where aesthetics is important. Fibroblastic and capillary proliferation related to this type of material occurs earlier in comparison with the other kinds.

It was easier to remove the silk stitch because there was only one thread. The amount of embedding of the silk suture was not evident in our study which was contrary to the assumption that suture material is embedded in mucus membrane. Nylon sutures were also easy to be removed but in $4 \%$ of the cases, only 1 string was cut, then there was more difficulty in removal of other string (we did cervical cerclage with nylon with double strings). The difference observed in both groups was not statistically significant.

Caesarean section was done in 11 cases. Majority of these were due to other obstetrical indications. Out of 11 , only 3 were done for cervical dystocia that had occurred because of severe fibrosis due to cervical cerclage. Full term normal delivery occurred in $46 \%$ of nylon group and silk group each. LSCS was required in $24 \%$ of cases in nylon group and $20 \%$ of silk group. Among the total $24 \%$ cases undergone LSCS in nylon group, cervical dystocia was the most common indication for LSCS (12\%) followed by twin pregnancy, breech pregnancy and android pelvis in $4 \%$ each. In silk group total $20 \%$ of cases were delivered by LSCS with fetal distress (8\%) as common indication followed by CPD and breech presentation. Intra operative bleeding was seen in $24 \%$ women from nylon group whereas in $12 \%$ women in silk group. The difference observed in nylon and silk group was statistically insignificant.

It may be suggested that in cervical incompetence the mechanical or biochemical properties of the cervix vary from those of the normal cervix, making possible a different pattern of labor. A recent study tested the connective tissue changes of the cervices of normal pregnant women and those of women with cervical incompetence. It was shown 
that, although the cervices of patients with cervical incompetence contained normal collagen concentrations, there was a high collagenolytic activity in these cervices, indicating a high turnover of collagen. This newly formed collagen had low strength and high distensibility properties. ${ }^{26}$ It has been shown further that women with a classic history of cervical incompetence have reduced elasticity as measured by intracervical balloons. Other authors have stated that the cervix does not dilate normally after a cerclage, presumably because of the foreign body reaction to the suture material and the formation of scar tissue. The scar tissue does not efface or dilate normally, but rather ruptures and "gives off" at the point at which the tensile forces of the uterine contractions overcome those of the tissue. ${ }^{27-29} \mathrm{We}$ could not confirm these claims; similar labor patterns were found in women with cervical cerclage and the comparison group. Cervical dystocia is commonly cited as a complication of cervical cerclage, causing faulty progression of labour and a higher caesarean rate. ${ }^{30-32}$

Takashi Yorifuji et al. ${ }^{33}$ conducted a retrospective study to determine the sustained effects of emergency cerclage using slowly absorbable monofilament sutures, changes in cervical length after cerclage. They concluded that absorbable monofilament suture appears useful for emergency cerclage. Vincenzo Berghella ${ }^{34}$ conducted a study to assess whether type of suture material affects cerclage efficacy for preterm birth prevention and they concluded that type of suture material may not affect ultrasound-indicated cerclage efficacy in high-risk women with short CL, but

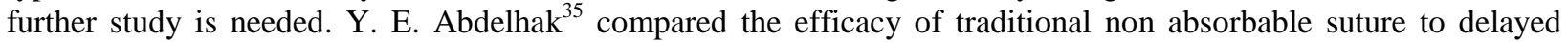
absorbable suture for used in McDonald cervical cerclage. They conducted a retrospective analysis of all cerclage procedures over a one year interval and stratified by the type of suture material. They reported that delayed absorbable suture material may be a reasonable alternative during cerclage placement, with the added benefit of spontaneous degradation versus surgical removal.

\section{Conclusion:-}

We thus conclude that average time taken for the procedure was significantly less with silk sutures while more intraop bleeding (24\% vs $12 \%)$ and complaint of discharge (20\% vs $12 \%$ ) was seen with nylon sutures. Both the suture materials were comparable in terms of operability, fibrosis, ease of removal and outcome.

\section{Recommendations:-}

We thus recommend that silk suture should be preferred in McDonald cerclage procedure, as significantly lesser time was required for the procedure and it also has a lower complication rate.

\section{Acknowledgement:-}

Authors acknowledge the immense help received from the scholars whose articles are cited and included in references of this manuscript. The authors are also grateful to authors/ editors/ publishers of all those articles, journals and books from where the literature for this article has been reviewed and discussed.

\section{Conflict of Interest:-}

None declared

\section{References:-}

1. Robert F, Mark SF, Jeremy T, Peter W. Transvaginal ultrasound in the management of women with suspected cervical incompetence. Br J Obstet Gynecol, 1996;103:921-24.

2. Paula J, Adams Hillard. Five-minute obstetrics and gynecology consult. Lippincott Williams \& Wilkins November 2010;482.

3. Shirodkar VN. A new method of operative treatment for habitual abortions in the second trimester of pregnancy. Antiseptic. 1955; 52:299-300

4. MacDonald IA. Suture of the cervix for inevitable miscarriage. J Obstet Gynaecol. 1957; 146:346-50.

5. Daskalakis G, Papantonious N, Mesogitis S, Antsaklis A. Management of cervical insufficiency and buldging fetal membranes. Am J Obstet\&Gynecol,. 2006;107:221-26.

6. Odibo AO, Alkousy M, Ural SH, Macones Ga. Prevention of preterm birth by cervical cerclage compared with expectant management a systematic review. Obstet GynecolSurv. 2003; 58: 130-36.

7. Rush, RW, Isaacs, S, McPherson, K, et al. A randomized controlled trial of cervical cerclage in women at high risk of spontaneous preterm delivery. Br J Obstet Gynaecol. 1984; 91:724.

8. McDonald IA. Cervical Cerclage. Clin. Obstet Gynaecol. 1980 7:461-9 
9. Phillip HE, Okewole IA. Cervical cerclage: What is the best suture? OA Case Reports. 2013 Oct 21;2(12):116.

10. Kattey K.A. Management of cervical incompetence (Powerpoint slides). 2015 April Retrieved from $\mathrm{http}: / / \mathrm{www}$.slideshare.net/katteysquare/management-of-cervical-incompetence.

11. Kaukab Naheed, Jehan Ara, Lubna Ejaz Kahloon. Effectiveness of Cervical Cerclage in Women with Cervical Incompetence. Journal of Rawalpindi Medical College (JRMC). 2008;12 (1):29-32.

12. Harlap and Davies, "Late Sequelae of Induced Abortion: Complications and Outcome of Pregnancy and Labor", American Journal of Epidemiology (1975), vol.102,no.3.

13. Morteza Tahmasebi, Mahan Bahrami et al. Correlation between the Risk of Incompetent Cervix and Maternal Age in Pregnancy. Iranian Journal of Radiology. 2011.

14. William's Obstetrics Twenty-Second Ed. Cunningham, F. Gary, et al, Ch. 9. Danforth/s Obstetrics and Gynecology Ninth Ed. Scott, James R., et al, Ch. 4.

15. Final report of the Medical Research Council/Royal College of Obstetricians and Gynaecologists multicenter randomised trial of cervical cerclage. MRC/RCOG Working Party on Cervical Cerclage. Br J Obstet Gynaecol. 1993;100:516-23.

16. Lazar P, Gueguen S, Dreyfus J, Renaud R, Pontonnier G, Papiernik E. Multicentred controlled trial of cervical cerclage in women at moderate risk of preterm delivery. Br J ObstetGynaecol. 1984;91:731-5.

17. Rush RW, Isaacs S, McPherson K, Jones L, Chalmers I, Grant A. A randomized controlled trial of cervical cerclage in women at high risk of spontaneous preterm delivery. Br J ObstetGynaecol. 1984;91:724-30.

18. Melamed N, Ben-Haroush A, Chen R, Kaplan B, Yogev Y. Intrapartum cervical lacerations: characteristics, risk factors, and effects on subsequent pregnancies. Am J Obstet Gynecol. 2009;200:388 e1-e4.

19. Parikh R, Brotzman S, Anasti JN. Cervical lacerations: some surprising facts. Am J Obstet Gynecol. 2007;196:e17-e18.

20. Landy HJ, Laughon SK, Bailit JL, Kominiarek MA, Gonzalez-Quintero VH, Ramirez M, et al. Characteristics associated with severe perineal and cervical lacerations during vaginal delivery. Obstet Gynecol. 2011;117:627-35.

21. BonfadiniBossi E, Migliavacca AE, Fagnani D, Salini P, Rella R, Garone G, et al. [Treatment of segmental cervical incompetence in pregnancy. Surgical indications, technic and results of 128 cervical cerclage operations]. Minerva Ginecol. 1981;33:385-8.

22. Harger JH. Comparison of success and morbidity in cervical cerclage procedures. Obstet Gynecol. 1980;56:543-8.

23. Kuhn RJP, Pepperell RJ. Cervical ligation: A review of 242 pregnancies. Aust N Z J Obstet Gynecol. 1977; $17: 79-83$

24. Ansari AH, Reynolds RA. Cervical incompetence: A review. J Reprod Med. 1987;32:161-70.

25. Golan A, Barnan R, Wexler S, Langer I, Bukovski I, David MP. Incompetence of the uterine cervix. ObstetGynecolSury. 1989; 44:96-107.

26. Rechberger $\mathrm{T}$, Uldbjerg N, Oxlund $\mathrm{H}$. Connective tissue changes in the cervix during normal pregnancy and pregnancy compli- cated by cervical incompetence. Obstet Gynecol. 1988;71:563-7.

27. Harger JH. Cervical cerclage. Patient selection, morbidity, and success rate. ClinPerinatol. 1983;10:321-41.

28. Harger JH. Comparison of success and morbidity in cervical cerclage procedures. Obstet Gynecol. 1980;56:543-8.

29. Kuhn RJP, Pepperell RJ. Cervical ligation: A review of 242 pregnancies. Aust N Z J Obstet Gynecol. 1977; $17: 79-83$

30. Ansari AH, Reynolds RA. Cervical incompetence: A review. J Reprod Med. 1987;32:161-70.

31. Golan A, Barnan R, Wexler S, Langer I, Bukovski I, David MP. Incompetence of the uterine cervix. ObstetGynecolSury. 1989; 44:96-107.

32. Parisi VM. Cervical incompetence and preterm labor. ClinObstet Gynecol. 1988;31:585-98.

33. Takashi Yorifuji, Shintaro Makino, Yuka Yamamoto, Toshitaka Tanaka, AtsuoItakura, Satoru Takeda. Effectiveness of delayed absorbable monofilament suture in emergency cerclage. Taiwanese Journal of Obstetrics \& Gynecology.2014; 53:382e384

34. Berghella V, Szychowski JM, Owen J, Hankins G, Iams JD, Sheffield JS, Perez-Delboy A, Wing DA, Guzman ER; Vaginal Ultrasound Trial Consortium. Suture type and ultrasound-indicated cerclage efficacy. J Matern Fetal Neonatal Med. 2012;25(11):2287-90.

35. Abdelhak YE, Sheen JJ, Kuczynski E, Bianco A. Comparison of delayed absorbable sutures vs non-absorbable suture for treatment of incompetent cervix. J Perinat Med. 1999;27(4):250-2. 